\title{
A Study on the Development of Leisure Sports Industry of China's Sichuan in the Age of Big Data
}

\author{
Chenliang Deng ${ }^{1, \mathrm{a}}$, Liang $\mathrm{Li}^{2}$ \\ ${ }^{1}$ Sports Department, University of Electronic Science and Technology of China, 610054 Chengdu, Sichuan, P.R. China \\ ${ }^{2}$ Department of Physical Education, Chengdu Sports University, 610041 Chengdu, Sichuan, P.R. China
}

\begin{abstract}
This paper mainly analyzes the development of leisure sports industry of Sichuan province in big data age in terms of opportunities, challenges, development trends and strategies. In this paper, based on the methods of documentary, interview, questionnaire and logic analysis, combing large data for broad influence and huge benefits of leisure sports industry, and then analyze its development trend and development strategy. The mega data age is expected to bring about favorable opportunities to leisure sports industry of Sichuan province, such as creating more value, contributing to the flexible distribution of resources and to the trend of new ways of thinking in the research on leisure sports industry. Both the application of mega data technology to and the research on the realm of leisure sports industry are faced with drastic challenges. From wide application, the processing mode, precise marketing and personnel training aspects analyzes the development trend of leisure sports industry in the era of big data. We should take corresponding counter-strategies, which include innovating leisure sports industry, implementing full application of mega data technology, increasing the supply of related professional talents, supporting the informatization of leisure sports industry and establishing a platform of information resource for leisure sports industry.
\end{abstract}

\section{Introduction}

Nowadays, the word "Big data" is increasingly mentioned to describe and define the stupendous data which arise with the information explosion. Big data, a collection of inestimable amount of data, is drawing public attention due to the possibility of excavating valuable information from it. The development of leisure sports industry is aimed at serving people's consumption need for body building, leisure and recreation. The big data age sees the drastic changes in the structure of leisure sports industry, and by taking advantage of advanced technology provides numerous leisure sports consumers with more human and tailored services that were unimaginable before. The development of leisure sports industry of Sichuan province in the specific circumstance of big data age is faced with both opportunities and challenges; therefore only by timely and effective elusion from risks and decisive and pinpoint grasp of opportunities can leisure sports industry of Sichuan province remain its leading role in the constantly changing sports market.

In the year 2013, big data sports caught people's attention and big data initiated a new era for the sports industry, and ever since then has become a fundamental means of making fortune in the sports market, making big data a heated topic that has roused extensive discussion. However, there have been very limited achievements in the realm of theory research, let alone specific research that integrates big data and leisure sports industry. In fact, in big data age the research on the development of leisure sports industry of Sichuan province not only provides a brand new perspective for theory research, but also serves as an important issue of practical value that can boost the development of leisure sports industry in Sichuan province.

\section{Opportunities and challenges for the development of leisure sports industry of Sichuan in big data age}

\subsection{More value created}

Different from cloud computing and the Internet of things in terms of storing and obtaining data, big data emphasizes how to excavate valuable data and then integrate and analyze related data and to make the data valuable resources for enterprises or managers. In addition, timely possession of these precious data enables enterprises and managers to promptly understand the current situation of market demand and comprehend consumers' needs and preference as well as their consumption orientation, and to further specifically distinguish the market and finally to manufacture

\footnotetext{
a Corresponding author: 850620188@qq.com
} 
products that can cater to consumers' taste [1].

Tailored products specially produced for individual consumers will be available in the near future, and will enjoy a even more promising prospect in leisure sports industry. By means of the sensors of the Internet of things, enterprises are able to obtain as much information about consumers' body as possible. They can also timely obtain consumers' related online information by using social network software such as micro-blog, Wechat, QQ, workout APP and Facebook. What's more, they can analyze and integrate the data with the help of software and provide the consumers with timely diagnosis of workout and health conditions as well as advice on workout and prescription. In this sense, more consumers will be attempted to get involved in and then at the same time create value for leisure sports industry.

\subsection{Flexibility in resource distribution}

Through the integrated application of smart perception, identifying technology as well as pervasive computing and ubiquitous network, the Internet of things makes the linkage of global resources possible. Based on the technology above, cloud computing redistributes global resources from "end" to "cloud" and contributes to the overall subversion, integration and innovation of the distribution of global resources. With the advancement of global network, cloud computing, the Internet of things and big data are playing an increasingly fundamental and instrumental role in leisure sports industry, and will not only bring drastic changes in the industry, but also improve people's leisure lifestyle in a healthier sense. Thanks to the new technology, the distribution of resources in leisure sports industry is no longer subject to geological location or physical condition. By contrast, based on demand, the distribution of resources presents a tendency to be flexible, which substantially promotes social benefits and public service standard.

\subsection{New ways of thinking in research}

Nowadays scientific data are exerting an increasingly obvious impact on scientific research. Data are not only the result of the latter, but serves as its foundation. In the realm of leisure sports industry, the research method characterized by mass data analysis has gradually been accepted. Big data age has witnessed the new thinking and research method in leisure sports industry. Firstly, by applying big data thinking to the research on leisure sports industry, the complete process of the research can be recorded, the original data and intermediate results as resources can realize all-round application, recycling ability can be prominently enhanced, and participation can be substantially improved. Secondly, in the setting of big data, research on leisure sports industry puts more emphasis on the collection and analysis of fragment data, stupendous data and non-structuralized data. Through fragmentized restructuring, tough or unpredictable problems can be revealed in depth, for instance, observing public awareness of participating in leisure sports through stupendous consumption demand, studying participation time according to the distribution of time in use and in vacancy of resources of leisure sports industry. Thirdly, in the setting of big data, by adopting computing and analyzing thinking in research on leisure sports industry, related propositions can be studied in terms of trend analysis.

\subsection{Challenges in the application of big data technology}

As the typical representative for new-generation information technology, big data technology can be possibly applied to each and every industry. In the realm of leisure sports industry, while big data technology is expected to bring full play in the future, it also is confronted with some challenges mainly in data collection, data storage, data process and visualization.

In terms of data collection, it is necessary to distinguish the data collected from the internet including the Internet of things and institution information system and to collect heterogeneous or even heteroid data. When necessary, compare the collected data with historical data so as to verify the comprehensiveness and validity of the data from different aspects. Besides, leisure sports industry, by no means an independent industry, is affiliated to sports industry, so it is difficult to separate the data related to leisure sports industry from the whole sports industry [2]. In terms of data storage, in order to achieve the targets of low cost, low consumption of energy and high reliability, redundancy configuration, distribution and cloud computing technology are usually adopted. In times of storage, data should be classified according to specific rules and then be added to the labels by filtration and de-weight for future retrieval.

As to data process, data of leisure sports industry involve numerous parameters, and their complexity lies in not only the data samples themselves, but also the interactive dynamism between multi-source isomerism, multi-entity and multi-space. Therefore it is very difficult to adopt the traditional methods in description and measure and it is necessary to integrate information based on loads of dynamic or even ambiguous data and then derive comprehensible content. As to visualization, it presents the results in a more direct manner which serves for better observation.

Currently, although there has been considerable advancement in computer intelligentization, only small-scale, structured or class-structured data can be analyzed, which is by no means data mining in depth. In addition, it is to the point of impossibility for the existing data mining algorithm to be applied to each and every industry.

\section{Trends of the development of leisure sports industry of Sichuan in big data age}

\subsection{Wide application of big data}

Big data technology will bring about its full play in 
leisure sports industry in the future. It can boost people's consumption in leisure sports, help them elude injuries and diseases, provide sports experience for the candidate consumers, and after all facilitate the development of related products in leisure sports industry. China online travel permeability is increase year by year, from $6.5 \%$ in 2012 to $10.8 \%$ in 2015 . Since 2016, the 5 trillion path of China's sports industry will rely on the five "tipping point", respectively is based on Internet +900 million mobile internet users in the community economy, based on event economic facility operation of large international events, leisure sports tourism economy, wear sports intelligence and training education campus economy.

Big data makes it possible to collect as much information about the consumers as possible and it enables consumers to optimize resource sharing and helps managers and enterprises with resource distribution in a more rational and reasonable way. By means of smart clothing equipment and based on the statistics targeted at the consumers, big data analysis technology is able to effectively modify consumers' leisure sports efficiency, help them elude injuries and diseases to the best, and finally improve their comprehensive consumption. Besides, big data analysis is expected to provide candidate consumers with completely new sports experience, detailed depth data and improve consumption possibility through pinpoint marketing.

With the ongoing trend of social digitization, leisure sports industry, on the data level, can learn from the concepts of related disciplines, and its future development should emphasize not only the basic research in big data technology in leisure sports industry, but also the application of the results of the basic research in technology research and practice.

\subsection{Diversified processing models}

With the diversification of processing models based on big data, Hadoop is no longer the only option for the construction of big data platform. In terms of application models, multiple choices, such as volume processing, flow computing and interactive computing, can satisfy different demands and are likely to further develop; in terms of realization technology, RAM computing, which enjoys remarkable improvement in performance compared with traditional hard-disk processing model, continues to be the main means of improving the processing performance of big data. A sustainable development of diversified models of big data will be integrated into leisure sports industry, in which a more diversified and balanced development and a conscious integration into big data technology.

\subsection{Increasingly valued pinpoint marketing}

The popularity of social networks and the development of the intelligent analysis of data make real time observation of individuals and groups possible, which provides a forceful tool to predict group behavior and understand personal preference. With the accelerating pace of life and the advent of mobile terminals, fragmentized consumption has become a trend in sports industry, that is, consumers are increasingly fascinated with individualized consumption. In order to take advantage of this trend and satisfy consumers' individualized needs, the provision of products, services and information in leisure sports industry should be tailored. Only if consumers pay for the tailored consumption that can truly serve their personal needs can the value of leisure sports products be revealed and that can the long-term development of it be guaranteed.

But the truth is that it remains a tough problem to exactly understand consumers' concrete needs. Fortunately, pinpoint marketing based on big data technology can help. If the depth value of leisure sports industry can be fully excavated through a best use of big data technology, then it is likely that new products and services that can satisfy consumers' needs will be developed, and that pinpoint and individualized advertisement delivery and custom-made services will be realized [3].

\subsection{An appeal for inter-disciplinary talents}

For big data, application is the drive while technology is the motor, and the two are equally important. It is talents and technology production manner that play a decisive role in technology. Geithner consulting firm predict large data will bring global 4.4 million new jobs in the IT and thousands of non-IT jobs. By the end of 2013, China has public business and the golf course has exposed construction of a total of nearly 700. In 2016 and 2020, officially became the Olympic Games to make a new cognition and attention of golf sports. According to the market rules of golf industry and economic development level, we forecast to 2020, mainland China golf course will not be less than 1500 , need tens of thousands of golf professionals. According to statistics, China's various provinces and cities with more than 100000 households sports fitness units, employees more than hundreds of millions of people. In the age of big data, to develop leisure sports industry, it is imperative to cultivate inter-disciplinary talents who have a good command of knowledge in leisure sports industry and big data technology, which calls for new models of talents cultivation and selection.

\section{Development strategy of leisure sports industry of Sichuan in the age of big data}

\subsection{Innovating leisure sports industry through proactive development of big data technology}

Big data, which is expected to be the significant carrier that leads future technological and social advancement, has made its presence in major civilian domain, such as finance, health, housing, transportation, education and sports, and is playing its role in the decision process of enterprises and the strategic layout of national development. Casting an eye over the globe, we can see developed countries such as the U.S., the U.K. and France, 
have successively issued related policies advocating rapid development of big data technology, and Japan and South Korea are also proactively preoccupied with big data technology practice. As to China, part of the financially affluent regions have also successively initiated plans for big data action or have established big data alliance in order to boost the development and application of big data technology. Innovation of leisure sports industry requires the support of big data technology, therefore it is suggested that big data strategies for leisure sports industry be formulated, top planning and design be further strengthened, and that efforts should be made to guide and promote the research in and application of big data to leisure sports industry.

\subsection{Fully applying big data technology to leisure sports industry}

How to conduct pinpoint distribution of the resources in leisure sports industry has long been a tough problem confronting relevant researchers. To resolve this problem, one of the solutions is to take advantage of information technology. By means of big data technology, data information can be timely collected and processed in real-time manner, which lays solid foundation for the scientific planning for leisure sports industry. Once the big data platform is established, it will unblock the channel for interest appeal and communication within the industry and formulate a automatic-response governance model for the industry. Based on an integration and analysis of the existing data about consumption, resource distribution and consumer group characteristics available on the internet, apply big data technology to industry decisions and management operation, implement a rational and effective distribution of resources and finally ensure equity in leisure sports industry.

\subsection{Increasing the provision of inter-disciplinary talents specializing in both big data and leisure sports industry}

The government and schools are supposed to take measures to increase the provision of talents specializing in both big data and leisure sports industry. First, implement education and cultivation plans. Relevant courses should be added to the list of the curriculum, and ensure an enlarged reserve of talents with knowledge both in sensing technology, data warehouse, data search, data mining and visualization, and in leisure sports and industry economy. Second, strengthen the introduction of talents. The implementation of various preferential policies and the construction of favorable development environment will attract worthy technicians both from abroad and home to join in leisure sports industry and strengthen the research strength in the industry. Finally, formulate relevant incentive measures. Enterprises are encouraged to popularize training in the realm of data analysis, adopt relevant technology to specify consumption demands, and innovative products and services.

\subsection{Supporting the informatization of leisure sports industry}

As an advanced kind of sports culture industry and the footstone for the sound development of sports industry, leisure sports industry is dependent on the strength of relevant authorities and enterprises for its development, especially the strength in research, development and innovation. Select some key supporting programs from all the leisure sports programs, increase promotion, packing and support, and take advantage of technologies like cloud computing, the Internet of things to boost research in and application of big data technology to leisure sports industry. Further develop the informatization of leisure sports industry, resolve the key problems such as resource sharing, industry distribution, consumer group characteristics and mining of newly-developing programs, and give priority to the application of big data technology to guide on leisure sports consumption and technology, injury prediction and control, product provision and distribution.

\subsection{Establishing information resource platform of leisure sports industry}

Information resource platform will facilitate information sharing and business coordination and promise to provide people with more convenient, qualified and effective services in leisure sports, satisfying the needs of different groups of people in body building, recreation, friends-making and public services. In order to serve the need for inter-departmental cooperative business based on leisure sports information, conduct designs from aspects of industry standard, consumption platform, social networks and data mining and application, and through data concentration mining improve data utilization and the management efficiency of leisure sport industry and public service level. Besides, formulate related regulations aimed at data sharing and information disclosure. For instance, compulsively force authorities or enterprises to disclose and share data; specify rewards and punishments, in which those who disclose information in a timely and reliable manner will be rewarded, while those who do not conform to the specification will be punished.

\section{Acknowledgements}

This research was financially supported by the Research Center for Sichuan Leisure Sports Industry of the Humanity and Social Science Research Base of the Education Department of Sichuan Province (Grant No. XXTYCY2016B08)

\section{References}

1. Xie J.L., Sun J.H., Cao L.. J. Shanghai Univ. S., 4, 59-63, 2015.

2. Sun J.J.. Guangming Daily, 2014.

3. Sun Y.L.. J. Publishing Research, 4, 5-8, 2013. 